\title{
Septal lesion effects on a two-way avoidance task with one-way avoidance task characteristics: A test of a fear-attenuation hypothesis
}

\author{
HEIDAR A. MODARESI, ROBERT P. HART, and LEONARD H. NENJA \\ Northern Illinois University, De Kalb, Illinois 60115
}

\begin{abstract}
Two experiments were conducted to assess the hypothesis that septal lesions result in a decrement in conditioned fear and to investigate whether the different effects of septal lesions in one-way and two-way avoidance tasks are due to some procedural differences between these two tasks. Experiment 1 compared the septal and normal control rats in a two-way avoidance task that incorporated a safe platform under the subject after a response but did not involve handling the subject (one-way analogue task). Experiment 2 investigated the effects of septal lesions in conventional two-way and one-way analogue tasks with two levels of shock intensity. The results indicated that, in the absence of a moving partition or electrified grids on top of the hurdle, the one-way analogue task enhanced the performance of both the normals and septals with both levels of shock intensity. Shock intensity had no effect in the one-way analogue task, but the more intense shock degraded the performance of both septals and normals in the two-way task. These results are not predicted by the fear-attenuation hypothesis. An alternative hypothesis in terms of the septals' deficiency in the utilization of spatial cues was tested and shown able to account for all of the present results.
\end{abstract}

Rats with septal lesions have been frequently found to acquire a two-way avoidance response faster than the normal control rats (e.g., Kenyon \& Krieckhaus, 1965b; King, 1958; Krieckhaus, Simmons, Thomas, \& Kenyon, 1964; Meyer, Johnson, \& Vaughn, 1970). In contrast, septal rats acquire a conventional oneway avoidance response more poorly than the normal control rats (e.g., Deagle \& Lubar, 1971; Kenyon \& Krieckhaus, 1965a; McNew \& Thompson, 1966; Vanderwolf, 1964). Since both these tasks involve identical escape-avoidance contingencies and are basically identical in response topography, the contradictory effects of septal lesions in two-way and one-way avoidance tasks pose serious difficulties for most theoretical analyses of the septal function in avoidance learning. The theoretical account of septal lesions that is presented by Kenyon and Krieckhaus (1965a) seemingly represents one exception to this general conclusion. According to this account, which may be referred to as "fear-attenuation" theory, septal lesions result in the attenuation of fear that is conditioned to the apparatus cues, for example, the grid floor and the warning signal (WS), that precede and accompany electric shock. Thus, the poor performance of the septal rats in one-way

The authors thank Robert J. Douglas for his critical review of this article. Requests for reprints should be sent to H. A. Modaresi, who is now at the Department of Psychology, Winthrop College, Rock Hill, South Carolina 29733. avoidance tasks is, according to this theory, simply due to the attenuated fear motivation at the start of a trial. In a two-way avoidance task, according to this theory, the attenuation of fear should, in addition to reducing the fear motivation, reduce the subject's tendency to freeze. The tendency to freeze does not normally take place in the one-way avoidance rat but is strong in the conventional two-way task, presumably because the latter task involves the conflicting requirement that the subject return to a place in which it has previously been shocked (Theios, Lynch, \& Lowe, 1966). Ablation of the septal area, which, according to the fear-attenuation theory, reduces fear, would also reduce the magnitude of conflict and freezing in the conventional two-way avoidance task and, thereby, would presumably more than offset the degrading effects of the septal lesions on the subject's motivation.

A major difficulty facing this, as well as other, theoretical accounts of septal lesions effects in avoidance learning, is that one- and two-way avoidance tasks, despite their apparent similarities, incorporate some important procedural differences. The commonly reported differences in the effects of the septal ablation in these two tasks may, therefore, be an artifact of these procedural differences (cf. Zucker, 1965). From an experimental standpoint, conventional one-way and two-way avoidance learning procedures differ in two important respects. First, the two-way avoidance subject is shocked in both compartments, whereas a one-way subject 
receives shock in only one compartment. The subject in a conventional two-way avoidance learning situation should, therefore, approach and, after a response, remain in a compartment that has previously been associated with shock and is, therefore, fear-provoking (McAllister \& McAllister, 1971). Moreover, since conditioning to spatial cues, for example, extra-apparatus and proprioceptive cues, can readily take place in rats (Olton \& Isaacson, 1968b; Olton \& Samuelson, 1976), one- and twoway avoidance tasks may be further differentiated in terms of the fear-provoking spatial cues that the subject in each task approaches in the process of responding, and in terms of the importance of these cues for the subject in locating the position of the compartment toward which a response should be directed.

Second, a conventional one-way avoidance subject receives handling at the end of each trial, whereas a two-way avoidance subject does not. Since damage to the septal region leads to hyperirritability (Brady \& Nauta, 1953; King, 1958), handling of the one-way subject with septal lesions may be an aversive event and have the effects of a punisher. In view of these procedural differences between the conventional oneand two-way avoidance learning situations, it is likely that, despite their apparent similarities, these learning situations involve different underlying processes that may interact with the effects of septal lesions. So long as the procedural differences and their associated processes in one-way and two-way avoidance tasks are not eliminated or their possible interactions with the effects of septal lesions are not satisfactorily explained, the comparisons of the oneand two-way avoidance studies in relation to the effects of the septal ablation are not valid (cf. Zucker, 1965).

One purpose of the present studies was to evaluate the effects of septal lesions in a conventional twoway and a locomotor avoidance learning situation that incorporated the basic characteristics of both oneway and two-way avoidance tasks without the usual procedural differences described above. Specifically, the latter task consisted of a basically two-way avoidance learning situation in which a retractable safe platform could be placed just over the grid floor in the to-be-entered compartment. The platform could then be removed from under the subject and, in order to escape or avoid shock, the subject would be required to enter the first compartment that now contained a safe platform. In the presence of a safe place after a response and during the intertrial interval (ITI), which is a most characteristic feature of the conventional one-way avoidance learning situation, the platformed avoidance task is analogous to the conventional one-way task and the avoidance performance is indistinguishable from that in a one-way avoidance situation (Modaresi, 1975, 1978; Modaresi,
Coe, \& Glendenning, 1975). Avoidance responding in the present apparatus without a safe platform, on the other hand, requires that the subject leave one compartment with a grid floor and enter another compartment also with a grid floor. These latter conditions constitute a conventional two-way task.

Another purpose of the present studies was to assess the efficacy of the fear-attenuation account of septal lesions. Specifically, since the one-way analogue avoidance procedures involve the presence of a safe place after a response, as in the conventional oneway procedures, and normally produce similar performance (Modaresi, 1975, 1978), the fear-attenuation theory should expect the septal rats to perform as in the conventional one-way task, that is, more poorly than the normal controls.

\section{GENERAL METHOD}

\section{Subjects}

The subjects were female hooded rats from the animal colony of the Psychology Department of Northern Illinois University. They were 151-211 days old at the start of the experiment and ranged in body weight from 240 to $300 \mathrm{~g}$ at the time of surgery. The rats were housed in group cages, 4-5 rats per cage, and had free access to food and water.

\section{Surgery and Histology}

Surgery was performed under ether anesthesia. The experimental (septal) subjects received stereotaxically placed bilateral lesions in the septal region by intracerebral insertion of a stainless steel electrode that was insulated except at the tip. The upper incision bar was positioned $5.0 \mathrm{~mm}$ above the interaural line. A direct current of 1.0-mA intensity was passed through the electrode for $15 \mathrm{sec}$, with a rectal electrode completing the circuit. The stereotaxic coordinates for the septal lesions were $2.2 \mathrm{~mm}$ anterior to bregma, $\pm 0.4-.5 \mathrm{~mm}$ lateral to the midline and $5.2 \mathrm{~mm}$ below dura. Half the animals underwent a control operation during which the electrode was inserted to a depth of $2.0 \mathrm{~mm}$ below the dura and withdrawn without delivering any current. Following surgery, all rats were allowed a 21-day recovery period in community cages, 4-6 per cage, with about half of the subjects in each cage being septal rats. Each of the subjects was handled for approximately 5 min during each of the last 3 days prior to the experiment proper.

At the conclusion of the experiment, the septal rats were sacrificed with an overdose of Nembutal. They were perfused via a cannula placed into the aorta with .99 saline solution followed by a $10 \%$ Formalin solution. Brains were stored in $10 \%$ Formalin for at least 4 weeks and were then blocked and embedded in paraffin. For each brain, a set of $10-\mu \mathrm{m}$-thick sections through the lesioned area was stained with Luxol-fast blue, counterstained with cresyl-violet, and then permanently mounted onto glass slides. Microscopic analysis of the lesions was made and the borders of the lesioned area were traced onto two-dimensional representations of the rat brain.

\footnotetext{
Apparatus

The apparatus, which is fully described elsewhere (Modaresi et al., 1975), basically consisted of two identical compartments $(23 \times 20 \times 29 \mathrm{~cm}$ high) made of flat black Plexiglas. The compartments were divided by a partition with an opening $(11.4 \times$ $12.6 \mathrm{~cm}$ high) located in its center that allowed for the subject's passage between the compartments. The bottom of the opening formed a hurdle $11.5 \mathrm{~cm}$ above the floor. The floor of each compartment was made up of nine stainless steel rods, $.08 \mathrm{~cm}$ in
} 
diameter, placed $.97 \mathrm{~cm}$ apart, center to center. To reduce the possibility of the subjects' perching on the hurdle, it was topped by two electrically chargeable grid bars.

Inside each compartment, $1.3 \mathrm{~cm}$ above the grid floor, there was a movable platform, made of flat black Plexiglas, which could be slid along tracks in the side walls and thus could be moved in or out of the back wall of the compartment. When a platform was completely inserted, it extended from one end of a compartment to a point $1 \mathrm{~cm}$ from the center partition. The end wall of each compartment, also made of flat black Plexiglas, could be moved back and forth just above the platform from one end to the center adjacent to the center partition and back to the original end position. A movable end wall, therefore, could function also as a barrier to block passage of the subject through the center opening during the ITI. In Experiment 2, however, a handoperated guillotine, instead of the movable end walls, was used to confine the subject to a compartment during the ITI. All other movable components were driven by reversible electric motors through racks and pinions. The full range of motion of a component, for example, removal of the platform from a compartment, took about $5 \mathrm{sec}$.

The interior of the apparatus was illuminated by a $7-\mathrm{W}$ red bulb that was located outside the apparatus at the level of the grid floor adjacent to the center partition. The illumination in the experimental room was provided by a $7.5-\mathrm{W}$ bulb placed $3 \mathrm{~m}$ in front of the apparatus.

A Grason-Stadler Model 700 shock generator and scrambler was used. The warning signal consisted of a 4-W light bulb below the grid floor under the middle of the end wall of the compartment from which a response was initiated.

\section{EXPERIMENT 1}

\begin{abstract}
Method
Procedure. Ten septal rats and 10 normal (sham-operated) control rats were used. All subjects were trained in a platformed twoway (one-way analogue) avoidance task. Each trial began with the onset of the WS light and the simultaneous backward movement of the end wall, which had been placed just behind the center partition. The WS-shock interval was $11 \mathrm{sec}$, during which the center opening remained unblocked so that the subject could cross over the hurdle and reach the platform in the goal compartment. A response in this interval constituted an avoidance and resulted in cancellation of the programmed shock and termination of the WS. If no avoidance response occurred, shock was applied to the grid floor and both the WS and shock remained on until the subject entered the goal compartment (escape response). The current to the hurdle grids was turned on only on escape trials and was coterminated with the floor shock. The shock intensity was a nominal $1.0 \mathrm{~mA}$. The appropriate end wall was always placed behind the center partition immediately after a response. The subject remained on the platform for $30 \mathrm{sec}$, after which the platform was removed and the subject remained on the grid floor undisturbed for an additional $30 \mathrm{sec}$ before the next trial began. The total ITI duration was, therefore, $60 \mathrm{sec}$. The purpose of the latter 30 -sec period was to reduce the possible effects of platform removal stimulation on the septal rats immediately prior to the start of a trial. This seemed necessary because septal rats are more irritable and sensitive to stimulations than normal rats (Brady \& Nauta, 1953; King, 1958; Thomas \& McCleary, 1974). The next trial was exactly the same, but in the reverse direction.

The subjects were run in random blocks of two in a single session of 30 trials.
\end{abstract}

\section{Results}

Anatomical. The septal lesions extended from approximately 3.2 to $.8 \mathrm{~mm}$ anterior to bregma, effectively destroying both lateral septal nuclei along their anterior-posterior extent. Frequently, they also included the ventral third of the medial septal nucleus (Figure 1). The damage to the hippocampal commissure was typically minimal, and the hippocampal formation, fornix, nucleus propius striae terminalis and the medial and lateral parolfactorial areas occasionally suffered minor invasion.

Behavioral. Figure 2 depicts the results of Experiment 1 in terms of the mean percentage avoidance responses of each group in blocks of five trials. The septal rats were clearly inferior to the normal control rats at all blocks of trials. A repeated measures analysis of variance on these data revealed that the effects of lesions $[F(1,18)=22.43, p<.001]$, trial blocks $[F(5,90)=15.88, p<.001]$, and the interaction between these factors $[F(5,90)=2.64, p<.03]$ were significant. Separate analyses on blocks of trials revealed that the control group outperformed the septal group in all but the first block of trials $\left[F_{\min }\right.$ $(1,18)=5.90, p<.05]$.

\section{Discussion}

The results of Experiment 1 are consistent with the fear-attenuation theory, suggesting that the septal lesions reduce the subject's fear motivation. However, an alternative explanation of the present results is possible. Specifically, the backward movement of the end wall from behind the center partition at the start of each trial constituted a particularly disturbing stimulus for the septal rats. This possibility is suggested by the finding that septal lesions enhance the subject's unconditioned reactions to various stimuli (Schwartzbaum, Green, Beatty, \& Thompson, 1967; Thomas \& McCleary, 1974).

\section{EXPERIMENT 2}

In this experiment, an attempt was made to replicate the procedures of Experiment 1 in the absence of the movable walls at the start of a trial and of the electrifiable grids on the hurdle. In order to discourage subjects from perching, the hurdle was filed to as narrow a width as possible. In addition, Experiment 2 evaluated the fear-attenuation theory by testing several hypotheses that were derived from that theoretical position. Specifically, septal rats were compared with control rats in both the conventional two-way and the platformed two-way (one-way analogue) avoidance tasks, with either a low (.3-mA) or a high (1.0-mA) shock intensity.

On the basis of the fear-attenuation theory, the following predictions were made. (1) The septal rats should outperform the control rats in the conventional two-way avoidance task with either the low or the high shock intensity. This prediction was, in part, based on the previous findings that septal rats are superior to normal control rats in the conventional 

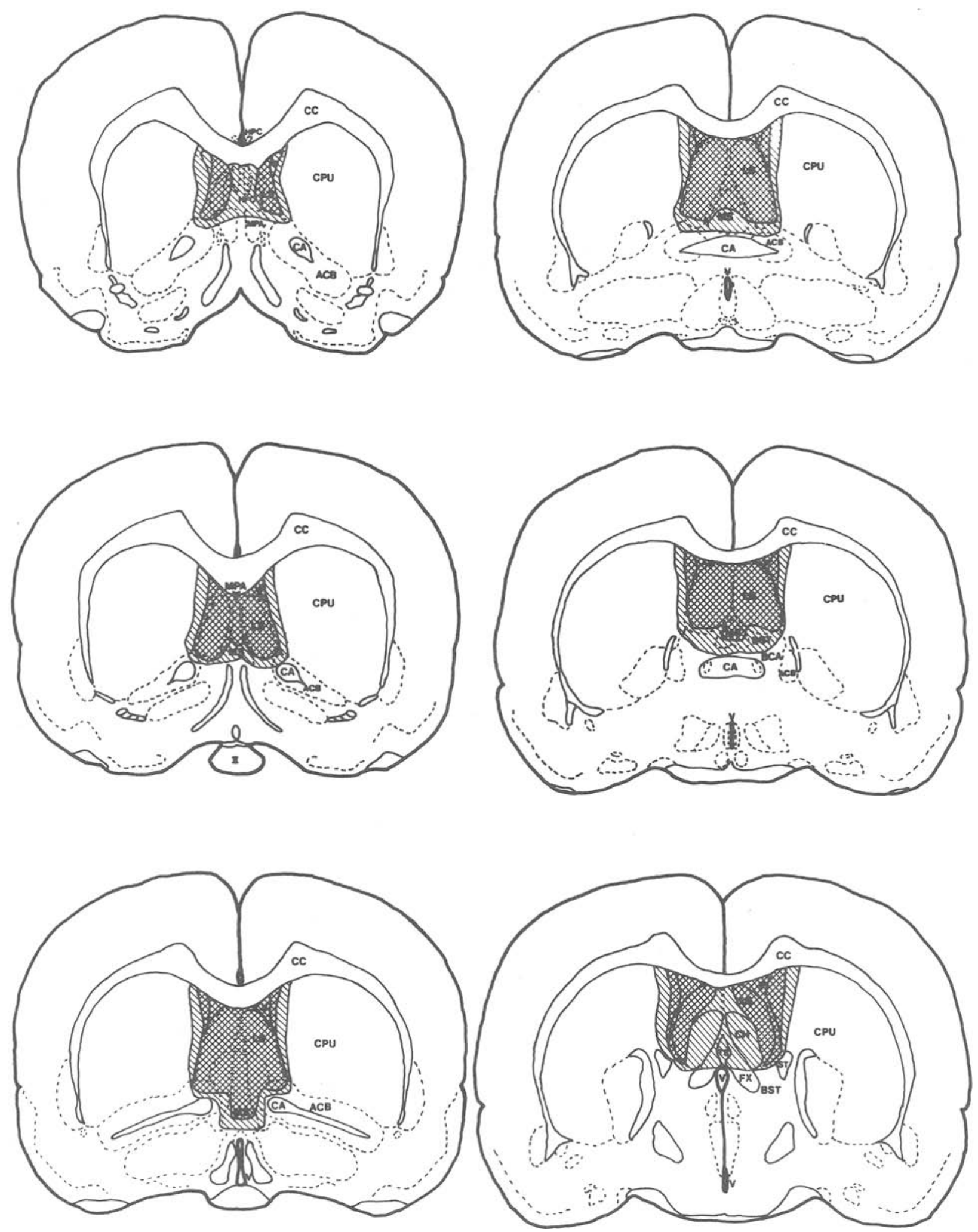

Figure 1. Schematic representation of the average (cross-hatched) and maximal (area with diagonal grid) extent of the septal lesions. Anterior to posterior sections are illustrated from top row left through bottom row left, then top row right through bottom row right. The illustrations represent sections at 3.0, 2.6, 2.2, 1.8, 1.4, and $1.0 \mathrm{~mm}$ anterior to bregma. 


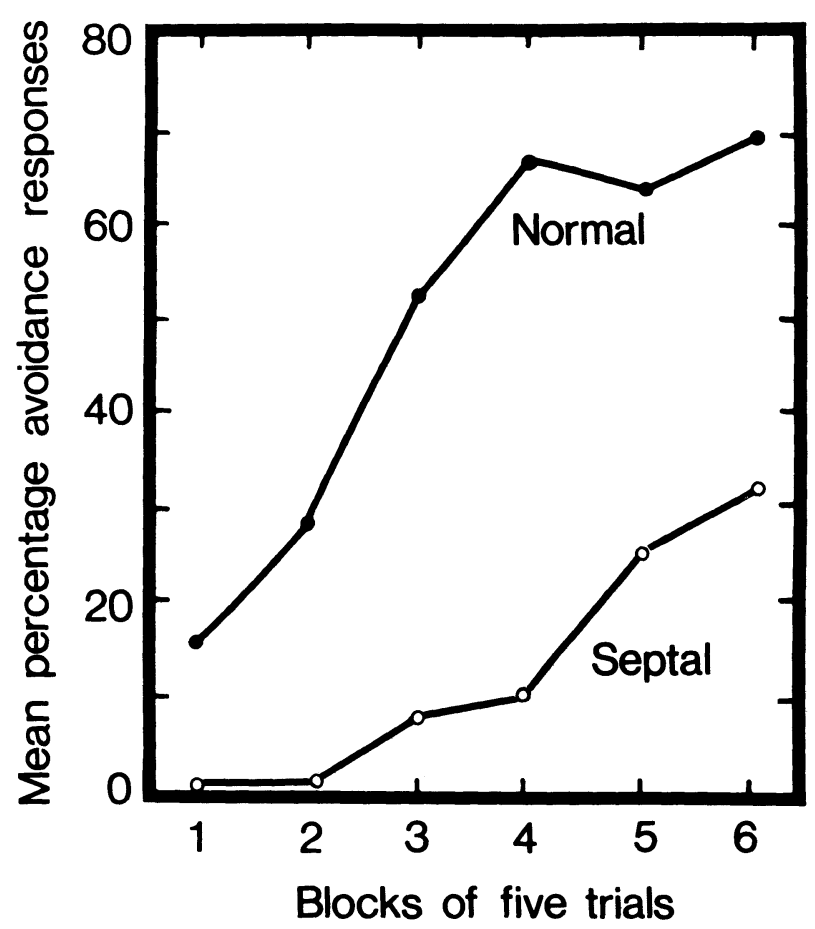

Figure 2. Mean percentage avoidance responses of the septal and normal control rats in blocks of five trials.

two-way avoidance learning situations that used even as low a shock intensity as .1-.4 mA (Krieckhaus et al., 1964; Miczek, Kelsey, \& Grossman, 1972). (2) The septal rats should perform more poorly than the normal controls in the platformed two-way procedures. This prediction follows from the fact that these avoidance procedures are analogous to the conventional one-way avoidance procedures. According to the fear-attenuation theory, the septal lesions, therefore, should primarily reduce the subject's fear motivation. Conversely, the normal rats, which presumably have greater fear motivation than the septal rats under both levels of shock intensity, should outperform the latter subjects in the platformed twoway avoidance task.

\section{Method}

Subjects and Apparatus. Forty normal (sham-operated) control rats and $\mathbf{4 0}$ septal rats were used. One septal rat had to be discarded due to apparatus failure. The apparatus differed from the one used in Experiment 1 only in that a hand-operated sliding guillotine door, instead of a movable end wall, was used to block the subject's passage between compartments and the electrified grids on top of the hurdle were removed.

Procedure. The design of the experiment was a 2 by 2 by 2 factorial, with the lesion (septal or sham-operated), shock intensity (.3 or $1.0 \mathrm{~mA}$ ), and task (one-way analogue or conventional twoway avoidance) as the factors. The subjects were assigned randomly to the eight possible groups: septal-.3P, septal-.3N, septal-1.0P, septal $1.0 \mathrm{~N}$, normal-.3P, normal-.3N, normal-1.0P, and normal$1.0 \mathrm{~N}(\mathrm{n}=10$ in each group except in septal-1.0N, which had only nine subjects). The portion of each group's name to the left of the hyphen designates the presence (septal) or absence (normal) of septal lesions; the right portion identifies the shock intensity
(.3 $\mathrm{mA}$ or $1.0 \mathrm{~mA})$ and the task $(\mathrm{P}$, presence of the platform immediately after a response for $30 \mathrm{sec}$ of the 60 -sec ITI duration, or $\mathrm{N}$, no platform during the ITI). A learning trial in all groups was basically the same as in Experiment 1 and began with the simultaneous onset of the WS light and raising of the guillotine door. The guillotine door was lowered immediately after a response. Avoidance training in the one-way analogue (platformed) conditions (i.e., P groups) was exactly the same as in the platformed groups of Experiment 1. The nonplatformed subjects (i.e., $\mathrm{N}$ groups) were treated identically to the $P$ groups except that the $\mathrm{N}$ subjects never received a safe platform. Following a response, these subjects were confined on the grid floor during the entire ITI of $60 \mathrm{sec}$ before the next trial began. All subjects received 40 trials in a single session. The subjects were run in blocks of eight, each block containing a randomly selected subject from each of the eight groups.

\section{Results}

Anatomical. Extent of septal lesions was similar to that reported in Experiment 1, as graphically represented in Figure 1.

Behavioral. Figure 3 depicts the mean percentage avoidance responses of all subjects in blocks of five trials as a function of the shock intensities, the lesions, and the avoidance tasks. These results suggest that the shape of the learning curves for the septal rats very nearly paralleled that of the normal control rats under all experimental conditions, while the septal rats nearly always outperformed the normal control rats. The effect of shock intensity seemed to depend on the task. That is, the higher shock intensity degraded the conventional two-way performance of both the septal and normal control rats, whereas it seemed to have a much smaller effect on the platformed twoway task. Finally, the subjects in the platformed two-

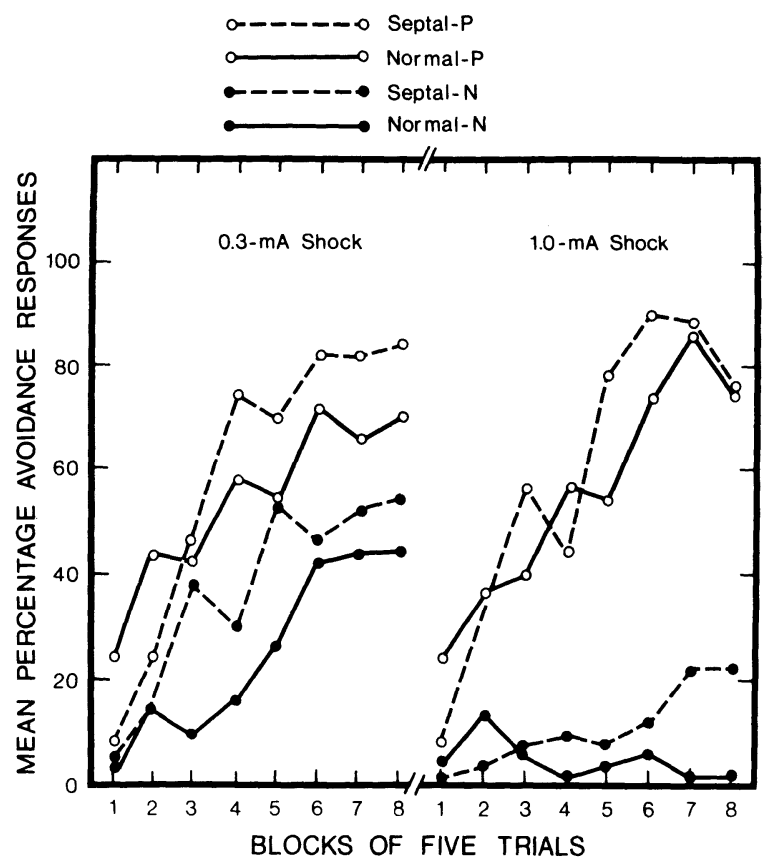

Figure 3. Mean percentage avoidance responses of the septal and normal control rats in blocks of five trials as a function of shock intensity and avoidance task. 
way task invariably outperformed those in the conventional two-way procedures.

These data were subjected to a repeated measures analysis of variance. The results indicated a significant effect of shock intensity $[F(1,71)=8.44]$, task $[F(1,71)$ $=100.42]$, trial blocks $(\mathrm{TB})[\mathrm{F}(7,497)=50.38]$, Shock Intensity by Task $[\mathrm{F}(1,71)=10.27]$, TB by Lesion $[\mathrm{F}(7,497)=4.21]$, TB by task $[\mathrm{F}(7,497)=8.96]$, TB by Shock Intensity by Task $[F(7,497)=4$.10] (all ps < $.01)$, TB by Shock Intensity $[F(7,497)=2.28 ; p<.03]$, and TB by Lesion by Shock Intensity by Task $[F(7,497)$ $=2.18 ; p<.04]$. Since the highest order interaction was significant, a factorial analysis was performed on each block of trials. The analyses resulted in significant effects of lesion in Trial Blocks 4-8 $\left[\mathrm{F}_{\mathrm{min}}\right.$ $(1,71)=4.44, p<.04]$, of shock intensity in Trial Blocks 4-8 $\left[\mathrm{F}_{\min }(1,71)=4.44, \mathrm{p}<.04\right]$, of task in Trial Blocks $1-8[\mathrm{~F}(1,71)=14.42, \mathrm{p}<.01]$, and of the Shock Intensity by Task interaction in Trial Blocks 4-8 $\left[F_{\min }(1,71)=7.76, p<.01\right]$. In order to determine the effects of septal lesions and shock intensity at different avoidance tasks in trial blocks in which the Shock Intensity by Task interaction was significant, a Shock Intensity by Lesion factorial analysis was performed for each of the two avoidance tasks in Trial Blocks 4-8. The results revealed that, in the platformed two-way avoidance task, there was no effect due to shock intensity but the septal rats reliably outperformed the normal subjects in Trial Blocks 4 and $5\left[\mathrm{~F}_{\min }(1,36)=4.11, \mathrm{p}<.05\right]$. In the conventional two-way task, on the other hand, the septal rats reliably outperformed the normal control rats in Trial Blocks 5-8 $\left[\mathrm{F}_{\min }(1,35)=5.03, \mathrm{p}<.04\right]$, whereas the shock effects were significant in Trial Blocks 4-8 $\left[F_{\min }(1,35)=6.84, p<.02\right]$.

\section{Discussion}

The present results indicated that the septal rats were superior to the normal subjects in the conventional two-way avoidance task. This finding is consistent with the results of a great majority of earlier studies on the effects of septal lesions on two-way avoidance learning. Blatt (1976) has suggested that rats with septal lesions perform better than normal rats only when the intertrial responses are punished. However, the superiority of the septal rats in the present study was obtained without any intertrial shock or punishment whatever. Blatt attempts to account for the usual superiority of the septal rats over the normal controls in two-way avoidance responding in terms of the suggestion that, while normal rats that are punished during the ITI suppress responding, septal lesions interfere with the suppression of ineffective (punished) responses. The present results, obviously, do not support this theoretical viewpoint.

The septal rats were superior, rather than inferior, to the normal rats in the platformed two-way task.
In terms of the fear-attenuation hypothesis, these results would, therefore, suggest that the septal subjects were not less fear motivated than the normal control rats. In fact, since the septals were superior to the normal controls in some of the platformed two-way avoidance trials, they may be said to have been more fear motivated. These results are inharmonious with the fear-attenuation hypothesis.

\section{GENERAL DISCUSSION}

The present studies were designed to answer two questions of theoretical importance. One question was whether or not the usual differences in the oneand two-avoidance performances of septal rats relative to those of normal controls would still be observed when some obvious procedural differences between the two tasks were eliminated. The second question concerned the efficacy of the fear-attenuation theory as an explanation for the effects of septal lesions in one- and two-way avoidance learning.

The results of the present studies indicated that the answers to both questions were in the negative. Unlike the usual performance deficits in the one-way avoidance task and enhancement in the two-way avoidance task in septal rats, the septal rats in Experiment 2 either outperformed or were no different from the normal control rats in either the conventional or the platformed two-way task. In Experiiment 1 , the septal rats were considerably inferior to the control rats in the platformed two-way procedures. It was suggested, however, that this large effect was due to the oversensitivity of the septal rats to the backward movement of a wall that functioned as an element of the WS compound. In Experiment 2, in which the moving wall was eliminated and no electrified grids were used on the hurdle, the septal rats, compared with the normal rats, were significantly superior performers from the fifth block of trials onward in the conventional two-way task and in Trial Blocks 4 and 5 in the platformed two-way task. Moreover, the performance of the septals in almost all blocks of trials in the latter task showed an obvious trend of superiority over that of the normal animals. These results, contrary to the fear-attenuation theory, suggest that septal rats were not less fear motivated than the normal control rats. Blatt (1976), who reviewed the literature of septal lesion effects in twoway avoidance learning situations, has pointed out similar contradictory results in some other studies. He has, thereby, suggested that fear be dropped as an explanatory concept in connection with the effects of septal lesions. The results of the present studies seem to support this suggestion. An alternative to the fear-attenuation explanation that would account for the present results may be based on the findings that various septal nuclei have both efferent and afferent 
connections to other subcortical regions, particularly to hippocampus (Carey, 1968; Lewis \& Shute, 1967; Macadar, Roig, Monti, \& Budelli, 1970; Petsche, Stumpf, Gogolack, 1962; Petsche, Gogolack, \& Van Zwieten, 1965; Powell, 1966; Raisman, 1966; Raisman, Cowan, \& Powell, 1966). Accordingly, each of these structures may function as a sort of relay station for the other (cf. Petsche et al., 1962). It follows that the behavioral effects of the septal lesions may be mediated via a joint septal-hippocampal system. Ablation of the septal region, therefore, may result in the behavioral consequences that are symptomatic of a dysfunction not only of septum, but also of hippocampus. In a recent review of the hippocampus literature, Black, Nadel, and O'Keefe (1977) have concluded that the animal with hippocampal lesions cannot employ information about places. In a two-way avoidance learning situation, for example, these animals cannot employ the place (spatial) cues in order to locate and enter the correct compartment on a trial but, rather, must rely on the apparatus cues. Intact animals, on the other hand, would respond to both the spatial and the apparatus cues (Olton \& Isaacson, 1968b).

Based on the assumption of a joint septohippocampal mediational system, the septal rats should also show some deficits in their ability to employ or to process spatial information. If true, then a conventional two-way avoidance learning situation should present a relatively more difficult task for the septal rats. Specifically, the normal rats, employing the spatial as well as the apparatus cues and, thereby, having fear conditioned to both types of cues (spatial and apparatus), must approach a relatively more aversive complex of stimuli than the septal rats, which can employ only the apparatus cues. The normal rats should, therefore, perform more poorly than the septal rats in a two-way task. This prediction is consistent with the finding that the difference between the normal and septal rats in a two-way task is due not to the superior performance of the septal rats, but to the inferior performance of the normal rats relative to the appropriate one-way-task control rats (e.g., Blatt, 1976; Schwartzbaum et al., 1967). In a conventional one-way task, on the other hand, the availability of the spatial cues to the normal animals but not to the septal rats could, among other factors, such as the different procedures in the two-way task, account for the superiority of the normal rats. That is, the normal subjects in a one-way task should have an easier task locating the proper to-be-entered compartment than the septal animals, and also should avoid a greater number of fear-provoking cues (i.e., both spatial and apparatus cues). The present theoretical position would, therefore, predict the inferior one-way and the superior two-way avoidance learning of the septal animals.
Some of the findings in Olton and Isaacson (1968a) provide a convenient means for assessing the present contention that the septal rats, like the hippocampectomized rats, show a deficiency in the utilization of the spatial cues. Olton and Isaacson found that animals with hippocampal damage were significantly more likely to make avoidance responses to either compartment of a two-way apparatus than the normal animals, which showed greater likelihood of avoiding toward one of the compartments. On the basis of these results and of the findings that hippocampectomized rats show a deficiency in utilizing place cues in the spontaneous alternation test procedures (Douglas, 1966; Douglas \& Isaacson, 1964), these authors concluded that hippocampally damaged animals cannot differentiate between the two compartments of a two-way avoidance apparatus as effectively as normal animals. On the basis of these findings, the theoretical position entertained in the present paper should predict that the septal rats show no preference for avoiding toward one or the other compartment of the apparatus, whereas the normal rats should exhibit such a preference. In order to assess this possibility, the mean absolute differences in number of avoidance responses toward the two compartments were calculated for the subjects in all groups of Experiment 2 (subjects that performed no avoidance responses were excluded). These values were as follows: septal- $.3 \mathrm{~N}=1.80$, normal- $.3 \mathrm{~N}=2.78$ $[\mathrm{t}(17)=1.31, \mathrm{p}>.10]$; septal-1.0N $=2.17$, normal-1.0N $=1.7[\mathrm{t}(10)=.64, \mathrm{p}>2.5]$; septal- $.3 \mathrm{P}=.70$, normal$.3 \mathrm{P}=5.50[\mathrm{t}(18)=5.05, \mathrm{p}<.01] ;$ septal $-1.0 \mathrm{P}=1.60$, normal-1.0P $=4.30[\mathrm{t}(18)=3.80, \mathrm{p}<.03]$. These results indicate that the septal subjects in the platformed two-way task performed like the hippocampectomized two-way subjects in Olton and Isaacson (1968a), whereas the septal rats in the conventional two-way task did not. This discrepancy could possibly be due to the rather poor avoidance performance of the conventional two-way subjects in the present Experiment 2 compared with the subjects in Olton and Isaacson's study. For example, all the normal and hippocampectomized subjects in the latter study met a $9 / 10$ avoidance criterion within an average range of 1.67 and 17.14 trials (only one group of normal rats required a mean of 49.20 trials to reach this criterion), whereas none of the $1.0 \mathrm{~N}$ subjects and only two of the $.3 \mathrm{~N}$ subjects of Experiment 2 reached such a criterion in $\mathbf{4 0}$ trials.

Within the present theoretical framework, the present findings may be explained in terms of the presumed differences in the spatial-cues utilization of the septal and normal animals. Specifically, the septals are presumed to be able to use and learn on the basis of only the apparatus cues, whereas the normal rats should learn on the basis of both the apparatus and spatial cues. Thus, the superior perfor- 
mance of the septal rats in the present conventional two-way task may be considered a result of the fact that the normal rats approached both fearful spatial and fearful apparatus cues, whereas, in contrast, the septal rats could utilize only fearful apparatus cues. The fact that the septals were superior to normals in the platformed two-way task may similarly be explained on the basis of the septal rats' inability to utilize, or have fear conditioned to, spatial cues. The finding that the septal rats performed better in the platformed two-way task than they did in the conventional two-way task is, according to the present view, because the septal subjects in the latter task had to approach fearful apparatus cues, that is, the grid floor, whereas in the former task, they approached safe apparatus cues.

\section{REFERENCES}

Black, A. H., NADEL, L., \& O'KeEfe, J. Hippocampal function in avoidance learning and punishment. Psychological Bulletin, 1977, 84, 1107-1129.

Blatt, R. C. Facilitation and nonfacilitation of active avoidance behavior of rats with septal lesions in the shuttle box and running wheel. Journal of Comparative and Physiological Psychology, 1976, 90, 704-713.

Brady, J. V., \& Nauta, W. J. H. Subcortical mechanisms in emotional behavior. Affective changes following septal forebrain lesions in the rat. Journal of Comparative and Physiological Psychology, 1953, 46, 339-346.

CAREY, R. J. A further localization of inhibitory deficits resulting from septal ablation. Physiology \& Behavior, 1968, 3, 645-649.

Deagle, J. H., \& Lubar, J. F. Effect of septal lesions in two strains of rats on one-way and shuttle avoidance acquisition. Journal of Comparative and Physiological Psychology, 1971, 77, 277-281.

Douglas, R. J. Cues for spontaneous alternation. Journal of Comparative and Physiological Psychology, 1966, 62, 171-183.

Douglas, R. J., \& IsaAcson, R. L. Hippocampal lesions and activity. Psychonomic Science, 1964, 1, 187-188.

Kenyon, J., \& Krieckhaus, E. E. Decrement in one-way avoidance learning following septal lesions. Psychonomic Science, 1965, 3, 113-114. (a)

Kenyon, J., \& Krieckhaus, E. E. Enhanced avoidance behavior following septal lesions in the rat as a function of lesion size and spontaneous activity. Journal of Comparative and Physiological Psychology, 1965, 59, 466-469. (b)

KING, F. A. Effects of septal and amygdaloid lesions on emotional behavior and conditioned avoidance responses in the rat. Journal of Nervous and Mental Disease, 1958, 126, 57-63.

Krieckhaus, E. E., Simmons, H. J., Thomas, G. J., \& KENYON, J. Septal lesions enhance shock avoidance behavior in the rat. Experimental Neurology, 1964, 9, 107-113.

LEwis, P. R., \& Shute, C. C. D. The cholinergic limbic system: Projections to hippocampal formation, medial cortex, nuclei of the ascending cholinergic reticular system, and the subfornical organ and Dupraoptic crest. Brain, 1967, 90, 521-540.

Macadar, O., Roig, J. A., Monti, J. M., \& Budelli, R. The functional relationship between septal and hippocampal unit activity and hippocampal theta rhythm. Physiology \& Behavior, 1970, 5, 1443-1449.

MCAlliste r, W. R., \& McAllister, D. E. Behavioral measurement of conditioned fear. In F. R. Brush (Ed.), Aversive conditioning and learning. New York: Academic Press, 1971.
McNew, J. J., \& Thompson, R. Role of the limbic system in active and passive avoidance conditioning in the rat. Journal of Comparative and Physiological Psychology, 1966, 61, 173-180.

Meyer, P. M., Johnson, D. A., \& Vaughn, D. W. The consequences of septal and neocortical ablations upon learning a twoway conditioned avoidance response. Brain Research, 1970, 22, 113-120.

Micze K, K. A., Kelsey, J. E., \& Grossman, S. P. Time course of septal lesions on avoidance, response suppression and reactivity to shock. Journal of Comparative and Physiological Psychology, 1972, 79, 318-327.

Modaresi, H. A. One-way characteristic performance of rats under two-way signalled avoidance conditions. Learning and Motivation, 1975, 6, 484-497.

Modaresi, H. A. Facilitating effects of a safe platform on twoway avoidance learning. Journal of Experimental Psychology: Animal Behavior Processes, 1978, 4, 83-94.

Modaresi, H. A., Coe, V. W., \& Glendenning, B. J. An efficient one- and two-way avoidance apparatus capable of producing identical one- and two-way avoidance performance. Behavior Research Methods \& Instrumentation, 1975, 7, 348-350.

Olton, D. S., \& IsaAcson, R. L. Hippocampal lesions and active avoidance. Physiology \& Behavior, 1968, 3, 719-724. (a)

Olton, D. S., \& IsAaCson, R. L. Importance of spatial location in active avoidance tasks. Journal of Comparative and Physiological Psychology, 1968, 65, 535-539. (b)

Olton, D. S., \& Samuelson, R. J. Remembrance of places past: Spatial memory in rats. Journal of Experimental Psychology: Animal Behavior Processes, 1976, 2, 97-116.

Petsche, H., Gogolak, G., \& Van Zwieten, M. A. Rhythmicity of septal cell discharges at various levels of reticular excitation. Electroencephalographical Clinical Neurophysiology, 1965, 19, 25-33.

Petsche, H., Stumpf, C., \& Gogolak, G. The significance of the rabbit's septum as a relay station between the midbrain and the hippocampus. I. The control of hippocampus arousal activity by the septum cells. Electroencephalographical Clinical Neurophysiology, 1962, 14, 202-211.

Powell, E. W. Septal efferents in the cat. Experimental Neurology, 1966, 14, 328-337.

Raisman, G. The connexions of the septum. Brain, 1966, 89, 317-348.

Raisman, G., Cowan, W. M., \& Powell, T. P. S. The experimental analysis of the efferent projection of the hippocampus. Brain, 1966, 89, 83-108.

Schwartzbaum, J. S., Green, R. H., Beatty, W. W., \& Thompson, J. B. Acquisition of avoidance behavior following septal lesions in the rat. Journal of Comparative and Physiological Psychology, 1967, 63, 95-104.

Theios, J., Lynch, A. D., \& Lowe, W. E., JR. Differential effects of shock intensity on one-way and shuttle avoidance conditioning. Journal of Experimental Psychology, 1966, 77, 294-299.

Thomas, J. B., \& McCleary, R. A. Fornical lesions and aversively-motivated behavior in the rat. Physiology \& Behavior, $1974,12,345-350$.

VANDE RWOLF, C. H. Effect of combined medial thalamic and septal lesions on active avoidance behavior. Journal of Comparative and Physiological Psychology, 1964, 58, 31-37.

ZuCKER, I. Effect of lesions of the septal-limbic area on the behavior of cats. Journal of Comparative and Physiological Psychology, 1965, 60, 344-352.

(Received for publication October 12, 1979; revision accepted February 20, 1980.) 